\title{
Mansonella perstans
}

National Cancer Institute

\section{Source}

National Cancer Institute. Mansonella perstans. NCI Thesaurus. Code C119326.

A nematode transmitted by the bite of Culicoides midges. The larvae mature in serous cavities, and the adult nematodes produce microfilariae that may be found in human blood and cerebrospinal fluid. Infections are typically asymptomatic. 